\title{
O PROCESSO DE APROVAÇÃO DO PLANO DIRETOR DE SÃO PAULO: O PAPEL DOS MOVIMENTOS SOCIAIS
}

\section{THE PROCESS OF APPROVAL OF MASTER PLAN OF SÃO PAULO: THE ROLE OF SOCIAL MOVEMENTS}

\author{
${ }^{1}$ Thaís Lopes Santana Isaías \\ ${ }^{2}$ Helena Carvalho Coelho
}

\section{RESUMO}

O espaço materializado como territorialidade em disputa produziu, com a modernização, desigualdades espaciais, fomentando a dicotomia centro-periferia. Com a proposta de atenuar os problemas gerados pela modernização tardia da cidade investiu-se no planejamento urbano. $\mathrm{O}$ modelo aqui implantado foi, em verdade, importado de países de Primeiro Mundo, o que implicou na introdução de um verdadeiro planejamento urbano fora do lugar. Essa proposta de salvação urbanística foi reproduzida nas prefeituras, que prontamente adotaram o Plano Diretor. Após mais de 10 (dez) anos de promulgação do Estatuto da Cidade, começaram as discussões a respeito da revisão dos planos, na qual (e não poderia ser diferente) teve relevância o processo de revisão do Plano Diretor Estratégico de São Paulo, que culminou na criação de um novo plano. Esse é, portanto, o objeto de estudo deste artigo, que objetivou traçar linhas gerais sobre o novo Plano Diretor Estratégico de São Paulo e entender, dentro desse contexto, a participação e papel dos movimentos sociais, utilizando-se da metodologia de análise de notícias publicadas na Folha de São Paulo entre 2012 a 2015.

Palavras-chave: Planejamento fora do lugar, Plano diretor estratégico de são paulo, Participação, Movimentos sociais, Ocupações urbanas

\begin{abstract}
The space materialized as disputed territoriality produced, with modernization, spatial inequalities, promoting the center-periphery dichotomy. With the proposal to mitigate the problems caused by late modernization of the city, investments were made in urban planning. The model implemented here was, in fact, imported from countries of "First World", which involved the introduction of a real "urban planning out of place." This proposed "urban salvation" was reproduced in the municipalities, which promptly adopted the Master Plan. After more than ten (10) years of enactment of the Statute of the City, discussions regarding the review of the plans, in which (and could not be otherwise) had relevance the review process of the Strategic Master Plan of São Paulo began, culminating in creating a new plan. This is therefore the object of study of this article aimed to outline provisions of the new Strategic Master Plan of São Paulo and to understand, in this context, the participation and role of social movements, using news published in Folha de Sao Paulo between 2012-2015 as analysis methodology.
\end{abstract}

Keywords: Planning "out of place", Strategic master plan of são paulo, Participation, Social movements, Urban occupations

\footnotetext{
${ }^{1}$ Mestranda em Direito pela Universidade Federal de Minas Gerais - UFMG, Belo Horizonte, (Brasil). E-mail: tutortreinamento@gmail.com

${ }^{2}$ Mestranda em Direito pela Universidade Federal de Minas Gerais - UFMG, Belo Horizonte, (Brasil). E-mail: tutortreinamento@gmail.com
} 


\section{INTRODUÇÃO}

O processo de modernização tardio e às avessas, típico da realidade brasileira, (re)produziu e agravou no espaço, enquanto territorialidade em disputa, a dicotomia centro-periferia. Os modelos de políticas públicas importados geraram ainda mais segregação do espaço, culminando em um cenário de "ideias fora do lugar e lugar fora das ideias".

O Planejamento Urbano brasileiro nesse contexto significou a orquestração de um modelo de cidade formal em contraste com a cidade informal - ignorada, na prática, por políticas públicas. A consolidação e a aplicação dos instrumentos urbanísticos no território reproduziu essa lógica. Após a promulgação do Estatuto da cidade houve uma explosão de Planos Diretores nos municípios - apostando-se no planejamento como proposta de organização e solução dos problemas urbanos. Este artigo se propõe, a partir das premissas expostas, apresentar linhas gerais acerca do Plano Diretor Estratégico de São Paulo para, então, aprofundar no processo de aprovação do Plano e na participação dos movimentos sociais, que, por meio da estratégia de ocupação das ruas, rompe com os mecanismos tradicionais de participação na esfera pública.

\section{PROBLEMATIZAÇÃO INICIAL: A REALIDADE BRASILEIRA E O "PLANEJAMENTO URBANO FORA DO LUGAR"1}

Após 20 (vinte) anos de ditadura militar, a redemocratização teve como auge a promulgação da Constituição de 1988, que significou a consolidação de demandas importantes para os movimentos sociais que participaram desse processo. Nesse sentido, a esperança depositada na CF/88, que trouxe em seu corpo direitos demandados por movimentos sociais, significou que a inclusão no texto constitucional parecia, em um primeiro momento, a garantia dos direitos na prática, já que "o processo constituinte brasileiro deu lugar a grandes inovações em relação à tradição

\footnotetext{
1 "As ideias fora do lugar e o lugar fora das ideias" foi uma frase cunhada por Francisco de Oliveira, como integrante da banca do concurso para professora Titular da USP, ao qual eu me submeti em 1999. Foi com essa frase que o lúcido professor resumiu o conteúdo da minha aula que versava sobre o deslocamento entre as matrizes que fundamentaram o planejamento e a legislação urbanos, no Brasil, e a realidade socioambiental de nossas cidades, em especial o crescimento da ocupação das favelas (MARICATO, 2002, 121-122).
} 
constitucional, possibilitando a inserção na Carta Magna de capítulos e de artigos que plantaram as sementes dos "novos" direitos" (SANTILLI, 2005, p. 57). No que tange às demandas dos movimentos urbanos, destacaram-se os capítulos da política urbana (Capítulo II, art. 182) e da política agrícola fundiária e da reforma agrária (capítulo III, art. 183) e, posteriormente, a inclusão no texto constitucional em 2000 do direito à moradia.

Seguido da CF/88, foi promulgado o Estatuto da Cidade (10.257/2001), sendo atribuído por muitos e durante muito tempo enquanto conquista do Movimento pela Reforma Urbana. É preciso dizer que na prática o Estatuto trouxe alguns avanços em seu texto, mas a aplicação de instrumentos importantes, em especial os que seriam relevantes para a reforma urbana, não ocorreu nos anos seguintes a sua promulgação. Assim:

A questão urbana e, particularmente, a agenda da reforma urbana, constitutiva da pauta das lutas sociais e fragilmente experimentada em esferas municipais nos anos 1980 e início dos anos 1990, foram abandonadas pelo por político dominante no país, em todas as esferas. (ROLNIK, 2013, p.09)

O Estatuto da Cidade reforçou, com a criação de inúmeros instrumentos, o "saudosismo" de transformação do Planejamento Urbano por vias meramente formais e a lógica pouco questionada por gestores de que diante da falta de planejamento deve-se apostar em mais planejamento, ao invés de lançar-se luz para outros mecanismos de solução. Nesse sentido veio também o Plano Diretor: "para fugir ao desprestígio dos planos não implantados, as denominações variam: Plano Diretor, Planejamento Integrado, Plano Urbanístico Básico, Plano Municipal de Desenvolvimento, entre outros" (MARICATO, 2002, p. 138).

O processo de planejamento demonstrou-se e consolidou-se com a vigência do Estatuto da Cidade em um verdadeiro "urbanismo ad hoc" de François Ascher. Como um exemplo desse processo (...) "no caso brasileiro, essa concepção foi entronizada pelo Estatuto da Cidade (...) com o nome de "operação urbana consorciada", que permite a aprovação de projetos que contrariem a legislação urbana vigente" (VAINER, 2013, p. 39).

O que se vê, assim, na condução da política urbana, é a reprodução da lógica dos instrumentos fora do lugar através de políticas públicas excludentes e uniformizantes, estritas de um ideário de cidade formal - a lógica, não poderia ser 
diferente, foi auspiciosamente incentivada por "uma grande e custosa campanha publicitária busca popularizar essas ideias", o investimento para "a construção da ideia da privatização como virtude e única saída" foi massivo a ponto de utilizar no Brasil "líderes de programas populares de auditório (Hebe Camargo, Ratinho, Ana Maria Braga)", sem que os telespectadores soubessem que o apresentador estava sendo regiamente recompensado para disseminar tais valores" (MARICATO, 2002, p.134).

A imposição de padrões e o processo de "normalização" desses padrões como ideais de "Primeiro Mundo" foram reproduzidos nas políticas públicas de habitação e urbanização no Brasil seguindo um modelo padronizante - espelhado no processo de privatização e investimento mínimo, sendo marcadas pela lógica do Estado Nacional moderno, que produz a hegemonia de sua administração com base no domínio e controle sobre a escala político-administrativa das fronteiras do território nacional e suas delimitações internas.

O resultado disso é que a homogeneização da população dentro de um mesmo território nacional se deu de forma a igualar os menos diferentes e a excluir os mais diferentes do status de cidadão e da fruição da cidade. A cidade, nesse sentido, não é a mesma para todos. A lógica de aplicação dos instrumentos urbanísticos está umbilicalmente ligada a essa distribuição de serviços e políticas públicas na construção e distribuição do espaço, do território como objeto de conquista. Desta forma, torna-se inegável argumentar que

Há uma lógica entre legislação urbana, serviços públicos urbanos (terceirização ou não), obras de infraestrutura e financiamento das campanhas eleitorais.

As cidades são o principal local onde se dá a reprodução da força de trabalho. Nem toda melhoria das condições de vida é acessível com melhores salários ou com melhor distribuição de renda. Boas condições de vida dependem, frequentemente, de políticas públicas urbanas - transporte, moradia, saneamento, educação, saúde, lazer, iluminação pública, coleta de lixo, segurança. Ou seja, a cidade não fornece apenas o lugar, o suporte ou o chão para essa reprodução social. Suas características e até mesmo a forma como fazem a diferença" (MARICATO, 2013, p. 19-20)

Tem-se, por conseguinte, planejamento para alguns e cidade para alguns, um modelo de conveniência em que "a importação dos padrões do chamado "primeiro mundo", aplicados a uma parte da cidade (ou da sociedade) contribuiu para que a cidade brasileira fosse marcada pela modernização incompleta ou excludente" (MARICATO, 2002, p. 123). Nos processos de construção das cidades (cidade formal e informal, a cidade formal como concentração dos investimentos públicos, que, 
mesmo "fora do lugar" e, por isso, repleto de distorções, existem, em concomitância com a cidade informal, que emerge e se estrutura a margem do direito posto), pôdese por vezes se falar em políticas que contemplam o direito à moradia entendido como conteúdo estrito (quatro paredes e um teto), mas não pautam o direito à cidade.

Sobre o processo de autoconstrução da cidade informal, Maricato adverte que a produção legislativa não abarca parte da cidade, sendo a realidade "ilegal" ignorada, "esta gigantesca ilegalidade não é fruto da ação de lideranças subversivas que querem afrontar a lei. Ela é resultado de um processo de urbanização que segrega e que exclui" (MARICATO, 2002, 155). Deve-se, portanto, partir da seguinte lógica:

“(...) priorizar o fato de que grande parte de nossas cidades é construída pelos próprios moradores em áreas invadidas - muitas delas ambientalmente frágeis - ou adquiridas de loteadores ilegais. Para a construção desses bairros não contribuem arquitetos ou engenheiros, tampouco há observância de legislação urbanística ou de quaisquer outras leis (...)" (MARICATO, 2013, p. 20)

Villaça, em 2002, já alertava sobre a mitologia do planejamento urbano materializado no Plano Diretor, mitologia que vem a ocultar os interesses por trás de tanta discussão acerca do planejamento urbano, os interesses de uma minoria em (re)ordenar a cidade conforme diretrizes postas pelo mercado. O planejamento materializa-se, assim, em mais do mesmo: expulsão das camadas pobres da população para a zona periférica, segregando a cidade e invizibilizando ao máximo o conflito, além de execução de propostas incapazes de atender a cidade real e suas transformações. Segue um pequeno trecho de entrevista acerca do projeto de revisão do Plano Diretor de São Paulo que exemplifica esse raciocínio:

\footnotetext{
Folha - Segundo a maioria dos urbanistas, São Paulo é um caos porque não foi planejada. 0 plano serviria para planejá-la. Villaça - Essa idéia de que plano diretor é um instrumento fundamental para guiar o crescimento da cidade, que é um instrumento global, essa tese de identificar o plano com o interesse público, isso tudo é a mitologia que se criou em torno do plano. E se criou para esconder o fato de o que está se cuidando, na verdade, é do interesse de uma minoria.
}

(...) Folha - O que o plano deveria ter para organizar a cidade? Villaça - Isso já é ter uma ambição muito grande. Você achar que um plano para o Estado ou para o país trará mudanças é muito complicado, principalmente se estivermos falando de um plano que extrapole um mandato.

É outra mitologia. Os planos mudam muito. Quem tem plano a longo prazo? O Metrô tem. E daí? Ele muda. A linha da avenida Paulista era para ligar a Vila Prudente à Vila Madalena. Só que o trecho da Vila Prudente sumiu. No último plano que vi, foi para o Sacomã. 
Outra coisa é a Lei de Zoneamento, que não tem prazo para vigorar. A primeira Lei de Zoneamento global foi aprovada em 1972. De lá para cá, o que ela já foi alterada... (DURAN, 2002) (grifos no original)

Em junho de 2013 vozes se levantaram nas ruas com gritos inflamados de diversas demandas, sendo elas em grande medida relacionadas à cidade e à frustração de tentativas de importação de modelos europeus de espaço urbano. Posteriormente a esse levante, diante da dificuldade de se solucionar os imbróglios urbanos no âmbito da cidade, as atenções voltaram-se a uma nova esfera: a Metrópole. É promulgada, então em 2015 a Lei 13.089/2015, o Estatuto da Metrópole, como "mais nova" proposta de salvação das demandas urbanas: mais um instrumento que demonstra a condução equivocada da política urbana brasileira. A preocupação que se quer levantar aqui é que "para não repetir as ideias fora do lugar é preciso ampliar o conhecimento da contraposição entre a história das ideias e a evolução da realidade empírica" (MARICATO, 2000, p. 173), e que uma lei, por si só, é apenas mais um instrumento que impulsiona a aplicação de "ideias fora do lugar e do lugar fora das ideias".

Diante dessa construção e embate entre as demandas urbanas e as políticas públicas surge um importante pano de fundo: a emergência, cada vez mais forte, de resistências na esfera urbana.

\section{ALgumas CONSIDERAÇÕES A RESPEITO DO NOVO PLANO DIRETOR DE SÃO PAULO}

Apenas para traçarmos linhas gerais, em trabalho a respeito da aplicação dos instrumentos urbanísticos e dos Planos Diretores, Neto, Krause e Balbim (2014) chamam a atenção para as dificuldades de aplicação desses instrumentos em municípios pequenos, em razão da dependência e reprodução de modelos do Governo federal e da realidade diferenciada de municípios de maior porte, que apresentam, em regra, Planos Diretores mais completos, que não necessariamente são de aplicabilidade integral em outros lugares:

Uma primeira constatação refere-se à forte influência das iniciativas do governo federal na estruturação da política urbana no nível municipal (...) 


\begin{abstract}
Verifica-se também que esses esforços e iniciativas não foram assimilados no plano municipal de maneira completa, seja em função das revelações obtidas por meio da análise quantitativa (...) em sua maioria, os PDPs se colocam como figuras autorizativas dos instrumentos, revelando pouco das estratégias de desenvolvimento urbano (...) municípios de maior porte em posições superiores na hierarquia da rede urbana apresentam maior presença dos instrumentos (...) o que denotaria um PD mais completo. (NETO; KRAUSE e BALBIM, 2014, p. 48-49)
\end{abstract}

Sendo São Paulo um município de alta complexidade e de grande porte, as dificuldades de implantação de um Plano Diretor são reduzidas pela dotação de mãode-obra qualificada e potencial de investimento. Por outro lado, os interesses de mercado fomentaram abismos sociais e dificultam a implantação de instrumentos como as ZEIS, impulsionando a segregação espacial da população lançada para áreas desvalorizadas e sem infraestrutura.

Ainda, a respeito da contextualização de São Paulo e do projeto de Plano Diretor aqui trazido à discussão, sobre esse Plano, sob a autoria de Nabil Bonduki em 2002, Flávio Villaça - orientador de Nabil Bonduki no doutorado na FAU-USP - já esclarecia as falácias construídas a partir da mitologia do Plano Diretor. Segundo ele, é um erro vincular a resolução de problemas da cidade aos planos, sendo que os países desenvolvidos postos como parâmetros utilizam-se de outros instrumentos. Conforme o autor, a ilusão de falta de planejamento, além de reproduzir mais do mesmo, trabalha a favor da manutenção de desigualdades e de interesses mercadológicos. Seguem trechos da entrevista com o autor:

\begin{abstract}
Folha - Segundo a maioria dos urbanistas, São Paulo é um caos porque não foi planejada. $O$ plano serviria para planejá-la. Villaça - Essa idéia de que plano diretor é um instrumento fundamental para guiar o crescimento da cidade, que é um instrumento global, essa tese de identificar o plano com o interesse público, isso tudo é a mitologia que se criou em torno do plano. E se criou para esconder o fato de o que está se cuidando, na verdade, é do interesse de uma minoria.
\end{abstract}

(...) Folha - O que o plano deveria ter para organizar a cidade? Villaça - Isso já é ter uma ambição muito grande. Você achar que um plano para o Estado ou para o país trará mudanças é muito complicado, principalmente se estivermos falando de um plano que extrapole um mandato.

É outra mitologia. Os planos mudam muito. Quem tem plano a longo prazo? O Metrô tem. E daí? Ele muda. A linha da avenida Paulista era para ligar a Vila Prudente à Vila Madalena. Só que o trecho da Vila Prudente sumiu. No último plano que vi, foi para 0 Sacomã. Outra coisa é a Lei de Zoneamento, que não tem prazo para vigorar. A primeira Lei de Zoneamento global foi aprovada em 1972. De lá para cá, o que ela já foi alterada... (DURAN, 2002) (grifos no original) 
Assim, no processo de aprovação do Plano Diretor de São Paulo, desafios reais eram enfrentados, tendo ocorrido forte participação dos movimentos sociais e, ao mesmo tempo, influência massiva dos interesses de mercado, além de um atraso de quase 10 anos da revisão do Plano Diretor:

No caso do PDE, esse processo teve que lidar com diversas condicionantes. Por um lado, o sentido de urgência: a revisão do Plano em vigor, naquele momento, estava atrasada 7 anos e, portanto, não havia tempo a perder. Ao mesmo tempo, era claro o sentimento de insatisfação em relação às dinâmicas da cidade, sobretudo a partir da forte produção imobiliária na década - a maior em pelo menos 30 anos. Ainda, era grande a demanda para a realização de um processo verdadeiramente participativo e mobilizador, que desse espaço e voz a todos os segmentos da sociedade e a todas as regiões da cidade. (PREFEITURA DE SÃO PAULO, 2015, p.6)

O Plano Diretor Estratégico aprovado tinha como objetivos previstos a garantia da melhoria da qualidade de vida de todos os bairros, limitação da produção imobiliária e preservação da qualidade de vida, além do estímulo ao uso misto dos espaços e geração de empregos, conforme se vê:

\begin{abstract}
O novo PDE tem como seu principal objetivo garantir a melhoria da qualidade de vida de todos os bairros. Nas áreas consolidadas, ele diminui o potencial construtivo e impõe um gabarito máximo garantindo um limite para a produção imobiliária e a preservação da qualidade de vida, ao mesmo tempo em que estabelece um aumento do potencial construtivo junto aos corredores de transporte público coletivo que chegam agora às periferias tendo grande estímulo ao uso misto e à geração de empregos, além de garantias de socialização do espaço público. É um plano para reequilibrar e humanizar São Paulo. (PREFEITURA DE SÃO PAULO, 2015, p.5)
\end{abstract}

Observa-se, portanto, a proposta de um plano que se mostrava aparentemente inovador através de integração de mecanismos econômicos novos como Parques Tecnológicos (art. 176, 186, 187) e Economia Criativa (art. 176, 182, 183, 184, 185, 346). Por outro lado, em relação aos mecanismos de participação popular pós-implementação, não havia inovação, haja vista que o plano reproduz a mesma lógica de câmaras técnicas, comissões e conselhos participativos.

Após críticas do projeto anterior de revisão do plano e forte pressão dos movimentos sociais, o processo de participação do Plano Diretor Estratégico mostrouse, então, mais plural e efetivo:

O fortalecimento do processo participativo resultou em distintas rodadas de discussão, oficinas e audiências públicas, reuniões com os mais diversos segmentos. Todo esse esforço foi recompensado: mais de 25 mil participantes e 10 mil contribuições, impactando significativamente a proposta que vinha sendo construída pelo Executivo (...) O processo na Câmara Municipal contou com 60 audiências públicas (com ampla divulgação 
nos meios de comunicação), consultas pela internet, direito à palavra assegurado a todos e transparência dos documentos, por meio de sua publicação no site da Câmara. (PREFEITURA DE SÃO PAULO, 2015, p.6)

Em verdade, inúmeros avanços no Plano só foram possíveis após a interferência popular, sendo importante verificar os meandros desse processo participativo, dos atores envolvidos no processo e empasses ocorridos, de forma a se clarear uma linha evolutiva entre o processo de aprovação e a participação dos movimentos sociais. É o que se faz no tópico seguinte, a partir de notícias da Folha de São Paulo de 2012 a 2015.

\section{O PROCESSO DE APROVAÇÃO DO PLANO DIRETOR E A PARTICIPAÇÃO DOS MOVIMENTO SOCIAIS DE 2012 A 2015}

A revisão do Plano Diretor, proposta no governo de Kassab foi, desde o início, marcada por forte tensão entre o governo e a sociedade civil. Em audiência realizada na Câmara "pessoas contrárias à revisão do plano pediram o microfone para atacar a proposta - a maioria para criticar a revisão de um projeto que sequer foi totalmente implantado". Muitos defendiam que a proposta de revisão seria, em verdade, um novo plano e questionavam a serviço de quem este novo instrumento estaria (BERGAMASCO, 2009).

A preocupação com a participação popular no processo de revisão do Plano mostrou-se decisiva desde o princípio. A atuação de ONG's e demais entidades civis foi primordial neste processo. Assim, já em 2010, o projeto foi declarado inválido judicialmente por ausência de participação popular adequada:

O juiz aceitou as alegações referentes à suposta falta de participação da população no processo - isso apesar de ter havido 45 audiências. Para o juiz, os encontros não cumpriram os requisitos exigidos (SILVA; MONTEIRO, 2010)

Após empasses no governo Kassab, a elaboração do novo PDE passou a ser de responsabilidade da nova gestão. Em 2012, o governo de Haddad definiu como prioridade a aprovação do plano no ano de 2013. Isso seria importante para a produção de efeitos ainda na sua própria gestão. Assim, deveria se considerar as dificuldades enfrentadas pela gestão anterior para aprovação e as novas dificuldades 
que tinham sido geradas pela necessidade de articulação entre os dois governos decorrente do processo de transição (BANDEIRA, 2012).

O coordenador de campanha e do grupo de transição do petista, Donato, 52 , diz que terá como atribuições no governo fazer a articulação entre as secretarias municipais e com a Câmara Municipal para colocar em prática promessas. (BANDEIRA, 2012)

A aprovação, no entanto, acabou se fazendo como criação de um novo Plano, em razão de o prazo para aprovação da revisão do Plano ter expirado e da ineficácia quanto à participação popular que gerou sua invalidação judicial. Conforme falas da época,

a revisão do Plano Diretor Estratégico (PDE) (...) é urgente para redefinir a estratégia urbanística de São Paulo. A reabertura do debate exige, no entanto, o encerramento da tramitação do projeto de lei $(\mathrm{PL}) 671 / 07$

(...)

foram cinco ações contra a tramitação. Apesar do esforço do Legislativo para aperfeiçoá-lo, o projeto se tornou um símbolo da falta de diálogo que marcou a administração passada. (BONDUKI, 2013)

Já na primeira apresentação do Plano Diretor, no dia 26 de setembro de 2013, durante o governo de Haddad, os movimentos sociais estiveram presentes. Um grupo de sem-teto e de representantes de movimentos pela moradia protestaram em frente à Câmara Municipal. Sobre os manifestantes, diz-se:

Cerca de cem pessoas que carregam faixas e cartazes com a frase "Queremos Moradia". Elas estão em frente ao prédio, interditando uma faixa do viaduto Jacareí (MOREIRA, 2013).

De imediato percebeu-se que o caminho até a aprovação seria turbulento e que era necessário não repetir os erros da gestão passada, viabilizando-se, portanto, um processo participativo amplo e efetivo.

A apresentação do Plano Diretor marcada para 12 de março de 2014 foi adiada devido à resistência de vereadores, sob o argumento de que haveria necessidade de maior participação. As discussões a respeito de pontos polêmicos 
como o "alargamento e alongamento das vias para a construção de corredores de ônibus - o que poderia causar desapropriação de 7.000 imóveis”, precisavam, então de mais debates (RODRIGUES, 2014).

Marcado por adiamento de sessões, manifestações e debates, "o futuro Plano Diretor da capital enfrenta lobbies que vão da regularização de igrejas e ocupações de sem-teto até a criação de um novo aeroporto, passando pela demanda do mercado imobiliário para poder construir mais" (RODRIGUES, 2014). Assim, a atuação do Movimento dos Trabalhadores Sem-teto foi primordial para reivindicar a aprovação do Plano. Sobre isso comentou-se: "a pressão dos sem-teto sobre os vereadores tem sido uma constante na reta final dos debates sobre o Plano Diretor". Isto porque, "para os sem-teto é fundamental que as zonas especiais de interesse social, onde serão construídas moradias populares, continuem no texto" (GERAQUE, 2014).

Entre as estratégias utilizadas, os movimentos sociais fizeram ocupações de áreas da zona sul, como em frente Câmara Municipal de São Paulo, para depois entrarem para acompanhar a sessão. Um grupo de 20 (vinte pessoas) dormiram dentro da Câmara: "nesta terça (24), os sem-teto reuniram 1.500 manifestantes em frente à Câmara. Bloquearam até a saída do estacionamento de vereadores". Os manifestantes, inclusive, anunciavam que ficariam o tempo que fosse necessário para aprovação do Plano:

"Nós vamos ficar o tempo que for necessário para a aprovação do Plano Diretor e da lei de zoneamento, porque dependemos desta alteração do zoneamento de terra para tocar o projeto de moradia", disse Beatriz" (MARTHA, 2014).

Após 09 (nove) meses de apresentação do projeto inicial, mais de 06 (seis) adiamentos de sessões pela Câmara Municipal, questionamento judicial e acordo entre PT e PSDB, foi aprovado em 30/07/2014 o PDE de São Paulo.

\footnotetext{
Esta lei é fruto de amplo processo participativo de revisão do Plano Diretor, realizado tanto no Executivo quanto no Legislativo. No total forma 114 encontros, mais de 10.000 contribuições e mais de 25.000 participantes, um pacto pelo desenvolvimento da cidade de São Paulo para os próximos 16 anos (PREFEITURA DE SÃO PAULO, 2015, p.70).
}

Por meio da participação popular conquistou-se diversos avanços, como a definição de que $60 \%$ das habitações construídas nas ZEIS teriam que ser destinadas 
a famílias com renda mensal inferior a três salários mínimos. Ainda, tratou-se de IPTU progressivo e desapropriação sanção e estabeleceu-se procedimento para despejos forçados de acordo com as normativas do Governo Federal (BOULOS, 2014). A respeito do processo de participação:

\begin{abstract}
Muito se falou das pressões para a aprovação do Plano. É verdade, os avanços obtidos não teriam sido possíveis se não fosse a intensa pressão popular. Mas esta foi apenas a pressão mais visível. Foram inúmeras mobilizações dos movimentos e uma participação ampla nas audiências públicas de debate do PDE. O MTST (Movimento dos Trabalhadores Sem Teto) permaneceu acampado em frente à Câmara durante sete dias até a aprovação do Plano.
\end{abstract}

Nem sempre porém a maior pressão é a mais visível. Em sua discussão o Plano foi objeto de uma pressão muito mais violenta por parte dos lobistas do mercado imobiliário. A pressão silenciosa de um engravatado pode ter mais efeito que o barulho dos descamisados. A pressão de bastidores dos empresários foi pesada e também incidiu no resultado final do Plano, como vimos no caso da Cota de Solidariedade. Ou alguém se atreveria a subestimar um setor que investiu que investiu mais de $R \$ 22$ milhões em doação de campanha para os atuais vereadores de São Paulo?

O PDE de 2014, apesar dos expressivos avanços, não reverte a lógica excludente de desenvolvimento da cidade. Nas atuais relações de força e com o atual sistema político nenhum Plano poderia fazê-lo. (BOULOS, 2014)

Nesse contexto, as manifestações prosseguiram mesmo após a aprovação do PDE, desdobrando-se em outras inegáveis conquistas dos movimentos sociais. Em entrevista concedida à Folha de São Paulo Guilherme Boulos afirmou:

\footnotetext{
"Agora, o MTST promete mais pressão. Não dissemos que o movimento iria dar uma trégua [após a demanda atendida a respeito do terreno invadido em Itaquera]. Só que não iria continuar fazendo ocupação semanal".
}

Também, a pressão do mercado das grandes empresas construtoras e incorporadoras pelo domínio das áreas centrais manteve-se forte e presente no novo PDE, razão pela qual os movimentos sociais não se afastaram, mesmo existindo uma primeira conquista formal, inclusive pela necessidade de se conquistar a efetivação dos instrumentos aprovados no novo Plano (KREPP; RODRIGUES; 2014).

\title{
CONCLUSÃO
}

A política urbana trazida com o modelo de modernização acarretou em um Planejamento Urbano excludente e divisor do território entre a cidade legal e a cidade 
ilegal. A importação de instrumentos urbanísticos de países desenvolvidos, nesse sentido, ampliou o processo de desigualdades. O Estatuto da Cidade consolidou vários destes instrumentos e apresentou o Plano Diretor como possibilidade de planejamento e resolução dos problemas das cidades. Assim, os Planos Diretores se multiplicaram pelos municípios, o que significou o espraiamento de "ideias fora do lugar e lugares fora das ideias".

O objeto deste artigo foi o Plano Diretor de São Paulo, sobre o qual foram traçadas linhas gerais a respeito dos objetivos do Plano e de comentários sobre o processo de revisão, processo esse que não alcançou seu objetivo devido aos entraves e ao lapso temporal, o que culminou na aprovação de um novo plano.

O processo de aprovação do Plano Diretor Estratégico foi marcado por manifestações intensas, forte participação dos movimentos sociais e interferência do mercado. A estratégia de ocupação urbana, que rompe com os mecanismos tradicionais de participação, com destaque para a participação do Movimento Semteto, foi primordial para pressionar e dar visibilidade ao movimento e a seus questionamentos. Esses questionamentos significaram uma maior pressão no poder legislativo, que, sob diversos pretextos, tentava manipular o processo de votação. Através da ação dos movimentos sociais diversas conquistas foram alcançadas, estando ainda em aberto se, na prática, estas conquistas serão implementadas. Acredita-se que a participação dos movimentos por outras vias que não as usuais, como através da ocupação das ruas, será imprescindível nessa nova etapa, já tendo militantes paulistanos anunciado jornadas de luta para os próximos anos.

\section{REFERÊNCIAS}

\section{BANDEIRA; Luiza. Novo secretário diz que vai tentar aprovar plano diretor já em} 2013. Folha de São Paulo: 2012. Disponível em: http://www1.folha.uol.com.br/cotidiano/1184709-novo-secretario-diz-que-vai-tentaraprovar-plano-diretor-ja-em-2013.shtml\#. Acesso em: 10 junho 2015.

BERGAMASCO, DANIEL. Plano Diretor perde foco e ganha bate-boca. Folha de São Paulo: 2009. Disponível em: <http://www1.folha.uol.com.br/fsp/cotidian/ff2906200914.htm>. Acesso em: 20 junho 2015. 
BONDUKI, Nabil. A revisão participativa do Plano Diretor. Folha de São Paulo: 2013. Folha de São Paulo. Disponível em: $<$ http://www1.folha.uol.com.br/ssp/opiniao/99144-a-revisao-participativa-do-planodiretor.shtml>. Acesso em: 10 junho 2015.

BRITTO, Patrícia. Elaboração de novo Plano Diretor é empurrado para próximo prefeito. Folha de São Paulo: 2012. Disponível em: <http://www1.folha.uol.com.br/saopaulo/1131219-elaboracao-de-novo-plano-diretore-empurrado-para-proximo-prefeito.shtml\#>. Acesso em: 20 junho 2015.

DURAN, Sérgio. Plano Diretor: Ex-orientador de doutorado do relator Nabil Bonduki diz que paga para ver projeto aprovado sair do papel. Folha de São Paulo: 2002. Disponível em: <http://www1.folha.uol.com.br/fsp/cotidian/ff0109200204.html>. Acesso em: 20 junho 2015.

GERAQUE, Eduardo. Sem-teto marcam ato para esta terça em frente à Câmara de SP. Folha de São Paulo. Disponível em: <www.folha.uol.com.br>. Acesso em: 15 junho 2015.

KREPP, Ana; RODRIGUES; Artur. Após aprovação do Plano Diretor, sem-teto voltam a protestar em SP. Folha de São Paulo: 2014. Disponível em: <http://www1.folha.uol.com.br/fsp/cotidiano/174960-apos-aprovacao-do-planodiretor-sem-teto-voltam-a-protestar-em-sp.shtml>. Acesso em: 20 junho 2015.

MARICATO, Ermínia. As idéias fora do lugar e o lugar fora das idéias. In: Arantes, Otília et al. A cidade do pensamento único. Petrópolis: Vozes, 2000, p. 121-192.

MARICATO, Ermínia. É a questão urbana, estúpido!. Cidades rebeldes: Passe Livre e as manifestações que tomaram as ruas do Brasil. In Ermínia Maricato et al. - 1ed. São Paulo: Boitempo: Carta Maior, 2013, p. 19-26. 
MARTHE, Alves. Sem-teto continuam acampados em frente à Câmara de São Paulo. Folha de São Paulo. Disponível em: <www.folha.uol.com.br>. Acesso em: 20 junho 2015.

MOREIRA, André. Sem-teto protesta na Câmara de SP durante apresentação do Plano Diretor. Folha de São Paulo: 2014. Disponível em: <http://www1.folha.uol.com.br/>. Acesso em: 01 junho 2015.

NETO, Vicente Correia Lima; KRAUSE, Cleandro Henrique; BALBIM, Renato Nunes. Instrumentos urbanísticos à luz dos planos diretores: uma análise a partir de um circuito completo de intervenção. Brasília: IPEA - Instituto de Pesquisa Econômica Aplicada, 2014.

PREFEITURA DE SÃO PAULO. Plano Diretor Estratégico do Município de São Paulo Lei no 16.050, de 31 de julho de 2014 estratégias ilustradas. Secretaria Municipal de Desenvolvimento Urbano: 2015.

RODRIGUES; Artur. Após sofrer pressão, Haddad adia entrega de Plano Diretor em SP. Folha de São Paulo. Disponível em: <www.folha.uol.com.br> Acesso em: 10 junho 2015.

RODRIGUES; Artur. Lobby para o Plano Diretor de São Paulo vai de igreja a aeroporto. Folha de São Paulo. Disponível em: <www.folha.uol.com.br>. Acesso em: 10 junho 2015.

ROLNIK, Raquel. Apresentação - As vozes das ruas: as revoltas de junho e suas interpretações. Cidades rebeldes: Passe Livre e as manifestações que tomaram as ruas do Brasil / Ermínia Maricato et al. - 1ed. São Paulo: Boitempo: Carta Maior, 2013, p. 7-12.

SANTILLI, Juliana. Socioambientalismo e novos direitos: proteção jurídica à diversidade biológica e cultural. São Paulo: Perópolis, 2005, p. 55-99. 
SILVA, José benedito da; MONTEIRO, André. Juiz invalida proposta de Kassab para Plano Diretor. Folha de São Paulo: 2010. Disponível em: <http://www1.folha.uol.com.br/fsp/cotidian/ff1208201019.htm>. Acesso 15 junho 2015.

VAINER, Carlos. Quando a cidade vai às ruas. Cidades rebeldes: Passe Livre e as manifestações que tomaram as ruas do Brasil. In Ermínia Maricato et al. - 1ed. São Paulo: Boitempo: Carta Maior, 2013, p.35-40. 